\title{
Peru earthquake, 8.0 Mw, registered by IMS infrasound stations Network
}

Darlan P. Fontenele, Lucas V. Barros, Brandow L. Neri, Juraci M. Carvalho, Diogo F. Albuquerque e Matheus F. Cruz University of Brasilia - UnB.

Copyright 2021, SBGf - Sociedade Brasileira de Geofísica

This paper was prepared for presentation during the $17^{\text {th }}$ International Congress of the Brazilian Geophysical Society held in Rio de Janeiro, Brazil, 16-19 August 2021.

Contents of this paper were reviewed by the Technical Committee of the $17^{\text {th }}$ International Congress of the Brazilian Geophysical Society and do not necessarily represent any position of the SBGf, its officers or members. Electronic reproduction or storage of any part of this paper for commercial purposes without the written consent of the Brazilian Geophysical Society is prohibited.

\section{Abstract}

Earthquakes are usually recorded by seismographic stations, but they can also be detected by infrasound stations. In this work, the existing synergy between seismic and infrasonic technologies is used to detect major earthquakes, exploring the capacity of an infrasound station to also detect, besides acoustic waves, ground vibrations produced by earthquakes. The infrasound is a sound in the frequency range below the limit of human hearing. The perception (or detection) of infrasound signals is made by microbarometers, which detect small variations of pressure in the atmosphere caused by natural or anthropogenic phenomenas. Originally, infrasonic technology was developed to monitor atmospheric nuclear explosions. This technology made a significant progress since the first nuclear explosions in the atmosphere. Recently, with the Comprehensive Nuclear Test-Ban Treaty (CTBT), infrasonic technology has become even more important, with the implementation of the International Monitoring System (IMS), a global network deployed by an organization linked to the United Nations. The IMS network is part of the Comprehensive Nuclear Test-Ban Treaty Organization (CTBTO), whose main purpose is to enforce the CTBT Treaty by the signatory countries. This global network is composed by 321 stations with sensors from four technologies, each one suitable for detecting nuclear explosions in a given environment.

Computational tools used in this work are from the NDCin-a-Box package (DTK-GPMCC and DTK-DIVA), made available by CTBTO to the signatory countries for reading, detect and analysis seismic and infrasonic signals.

It was used data from the M8 Peru earthquake of May 26, 2019. Detections related to this event were investigated in the ten nearest infrasound stations of the IMS Network surrounding the epicenter. However, the event was recorded only at 4 stations, all of them located at epicentral distances up to about $3,000 \mathrm{~km}$. The wave parameters obtained by the infrasound stations are compatible with those obtained from seismic stations.

\section{Introduction}

The International Monitoring System (IMS) Network was created as part of the obligations to comply with the Total Nuclear Test-Ban Treaty - CTBT, which was opened for signature in July 1996 at the United Nations (UN) headquarter. The Treaty will enter into force with the signature and ratification of all CTBT Annex 2 countries.

The IMS Network was designed to cover the entire planet, monitoring all possible environments for carrying out nuclear tests above $1 \mathrm{kt}$ : land surface, water masses and atmosphere.

A specific monitoring technology is used for each environment, which can use mutual synergy to improve the detection, discrimination and location of a nuclear test.

Countries that sign and ratify the Treaty must fulfill obligations inherent in the Treaty. Among them, the maintenance of the IMS stations installed within their territories, in addition to the transmission of the data generated by these stations to the International Data Center (IDC), located in Vienna - Austria.

For the materialization of the Treaty, the Provisional Technical Secretariat (PTS) was created, with the mission to implement and maintain the IMS Network and the IDC before the treaty comes into force.

The technologies used to monitor the nuclear tests are: seismic, hydroacoustic and infrasound, in addition to that, a fourth technology (Radionuclides), with the mission to confirm the occurrence of a nuclear test (Marty, 2019). A brief description of each technology is below.

Seismic technology (170 stations) is used to detect nuclear tests under (and also above) the Earth's surface and can also detect explosions inside the oceans, depending on the distances (Barros et al, 2020).

Hydroacoustic technology (11 stations) is used to detect explosions under the aquatic masses. They are high sensitivity stations and cover all oceans (Brown, 2014).

The infrasound technology (60 stations) is used to detect nuclear tests at the atmosphe. It can also detect subsurface explosions, as well in the oceans, depending on the power of the explosive yield (Dahlman et al, 2011). Fig. 1.

Finally, radionuclide technology is based on stations and laboratories for analyzing atomic particles that are released by nuclear explosions. These particles spread in 
Peru earthquake, mag. 8.0 Mw, registered by infrasound stations of the IMS Network

the atmosphere and can travel long distances, depending on climatic conditions, in special the wind speed. There are 80 stations and 16 laboratories.

\section{Synergy between seismic and infrasound technologies}

In general, synergy is the effect of contribution effort or mutual cooperation between different process or issues. The synergy between seismic and infrasonic technologies is because it is possible events be detected by both technologies. One can contribute with information to the other.

The spread of infrasound waves depends heavily on climatic factors, such as air temperature, wind speed and direction. The waves propagate through the atmosphere, mainly at altitudes ranging from $50 \mathrm{~km}$ to $100 \mathrm{~km}$ (between the upper stratosphere and the lower mesosphere) and also more than $100 \mathrm{~km}$ (in the thermosphere), which can be refracted on the Earth's surface at great distances from the source (Le Pichon et al, 2019).

The infrasound can provide unique data on extreme weather events, such as meteor impacts, severe storm systems, man-made explosions, volcanic eruptions, among others. The use of infrasound for the detection and events location requires high quality of atmospheric temporal and space models. To reach these levels of quality, infrasound waves generated by Ground Truth (GT) events (Gibbons et al, 2019), events for which the time and location of their occurrence are precisely known, enable the study of the atmospheric models and evaluate the performance of an infrasound network.

Earthquakes can also generate infrasound waves, depending on the characteristics of the seismic source. Magnitude, depth, and location are some of the factors that can contribute or facilitate the generation of infrasound (Park and Stump, 2014).

At the interface between two media (discontinuity), energy can transfer from one medium to the other. An example is the transfer of energy from the ground to the atmosphere. Ground movements caused by different seismic sources, especially large earthquakes, and explosions, can generate infrasound waves classified as local, epicentral and diffracted. Local infrasound waves are detected at infrasound stations when the seismic wave energy is coupled to the atmosphere in the vicinity of the receiver (Kim et al, 2004). The epicentral infrasound is generated near the source, where a large mass of land moves and couples the energy released by the earthquake to the atmosphere. The energy associated with the movement of the soil around the epicenter disturbs the air and the acoustic energy is radiated through the atmosphere as infrasound waves (Green et al, 2009; Arrowsmith et al, 2012). The diffracted infrasound is generated by secondary sources, such as mountain ranges (Cook, 1971; Le Pichon et al, 2002). The diffracted infrasound waves have a mixed propagation that consists of portions of the path in the soil and in the atmosphere (Donn and Posmentier, 1964; Cook, 1971).
Sensors for detecting infrasonic signals, microbarometers, can be sensitive to ground movements caused by the passage of seismic waves. Some models of microbarometers have constructive characteristics that allow this disposition to detect seismic signals, which is the case of some models currently used at the infrasound IMS stations., not discussed in this work. Some tectonic seismic events can be better detected than others, depending on the source magnitude, depth and epicentral distance.

\section{Detection of infrasonic signals}

Infrasound stations are arrays formed by elements sensitive to variations on the acoustic pressure in the atmosphere, whose frequency band delimited by the IMS requirement is 0.02 and $4 \mathrm{~Hz}$ (Mialle et al, 2019).

A typical infrasound station is formed by several elements, arranged in a defined spatial conformation. It can be triangular (up to 4 elements) and, sometimes, are polygons formed by many elements. Each element consists of a barographic sensor (microbarometer), a signal digitizer, a power system (based on solar panels, batteries and charge controller), a data transmission system and an acoustics filtering system to reduce noise from local wind turbulence (Walker and Hedlin, 2010). There is usually a meteorological station installed at the central element of an array.

Most infrasound stations used in this work have a triangular shape, with one element at the center of the triangle. For detection of infrasound signals with a certain wavelength, the array aperture is around $2 \mathrm{~km}$. An infrasound array is like a sensitive acoustic antenna, tuned at some infrasound wavelength. It is important to highlight that the used infrasound stations in this paper utilize microbarometer models sensitive to the passage of seismic disturbances.

\section{Data}

The data used are the waveforms of the earthquake occurred $78 \mathrm{~km}$ from Laguna - Peru, on 05/26/2019, at 07:41:15 (UTC). Its magnitude was estimated to $8.0 \mathrm{Mw}$ by the United State Geological Survey - USGS. The epicenter was located at $5,812^{\circ} \mathrm{S}$ and $75,270{ }^{\circ} \mathrm{W}$ and the hypocenter was about $120 \mathrm{~km}$ deep. This earthquake occurred along to a normal fault in an intermediate zone, within the subducted lithosphere of the Nazca techtonic plate, which produces frequent earthquakes at focal depths between $100 \mathrm{~km}$ and $150 \mathrm{~km}$, commonly called earthquakes of intermediate depth. They usually cause less damages to the surface but can be felt over great distances. Fortunately, however, it did not cause any death. The choice of the event for the study was based on the available data (whose seismic source parameters were known), in the magnitude - which we think should be quite expressive, to the point of enabling, in principle, the event to be detected by infrasound stations over great distances - and the existence of infrasound stations within a pre-determined radius. There was no concern about choosing a specific depth range (the hypocenter). 


\section{Methodology}

The ten closest IMS infasound stations were selected for this study with distances ranging from $1,372 \mathrm{~km}$ to 6,150 $\mathrm{km}$, Table 1 and Fig. 1. For each infrasound station, parameters were obtained for a comparative evaluation with seismic technology, such as back azimuth, predominant frequencies in the PMCC (Progressive MultiChannel Correlation) families and apparent velocity of the seismic waves front and the acoustic waves front. There was no record of the studied event, neither of the seismic waves nor of the infrasonic acoustic wave, in most of the infrasound stations surveyed, most likely due to the attenuation of the waves and/or due to meteorological conditions that affected the propagation path in the atmosphere towards to these stations. These reasons will not be discussed in this paper.

Table 1 - Infrasound stations used in the investigation of signals (seismic and infrasonic) generated by the Peru earthquake. The highlights show the stations that recorded the earthquake.
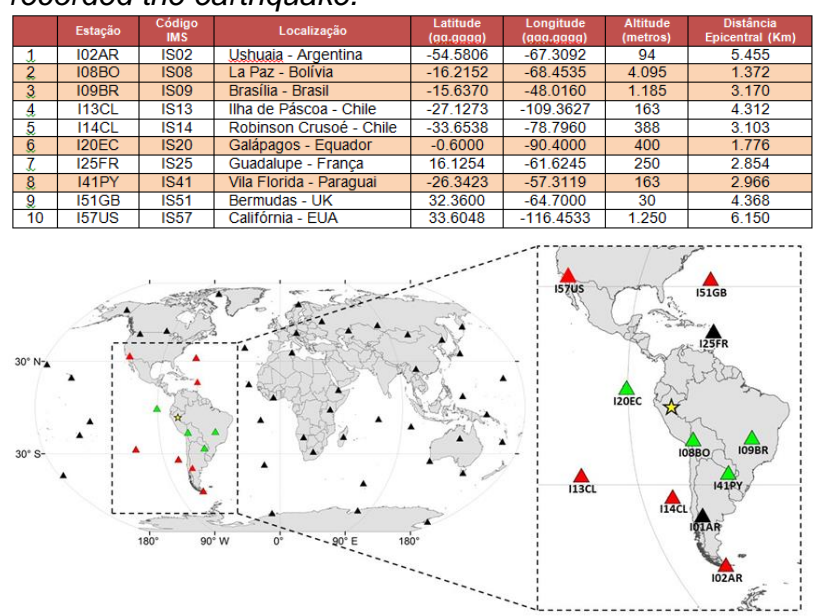

Fig. 1 - Global Infrasound Network. In detail, used infrasound stations. Yellow star indicates the earthquake location under this study. Green triangles denote the stations that recorded the earthquake signals. Red triangles are the stations that did not record the event and the black triangles are the stations that data was not available.

The capability of the IMS infrasound stations to detect events of interest depends heavily on the environmental noise (mostly wind), which is generally incoherent, and on the coherent signals detected in an array (Ceranna et al, 2019). In this way, we searched, at each station, for the coherent signals detected within the expected time period for the arrivals of the fronts of seismic and infrasonic waves at each station, generated by the chosen event. The DTK-GPMCC and DTK-Diva softwares package were to perform detections by means of signals cross correlations on the infrasound station elements. The detected pixels form the PMCC families, which show different information about the recorded signals. The coherent signals can therefore be differentiated according to their frequencies, expected arrival time and azimuth signature (Blanc et al, 2018).
The algorithm used, PMCC, was initially developed for the detection of seismic events and, later, adapted for the detection of infrasound signals. This method proved to be efficient for the routine identification of coherent low amplitude signals contaminated by incoherent noise (Mialle et al, 2019). The initial implementation of the PMCC used a series of linearly spaced frequency bands that, in practice, due to computational limitation, had the disadvantage of requiring several runs to cover the broadband frequency of interest $( \pm 0.02-4 \mathrm{~Hz})$. To overcame this limitation, the PMCC algorithm was improved using windows of variable length and frequency bands with logarithmic spacing (Brachet et al, 2010; Le Pichon et al, 2010), allowing the entire range of frequencies of interest to be processed efficiently on a single computational run. Fig. 2 shows the frequency bands selected in the signal processing at all stations used in this work, as well as the amplitude and phase responses for each band. These frequency bands originate from the model provided by IDC within the DTKGPMCC package.

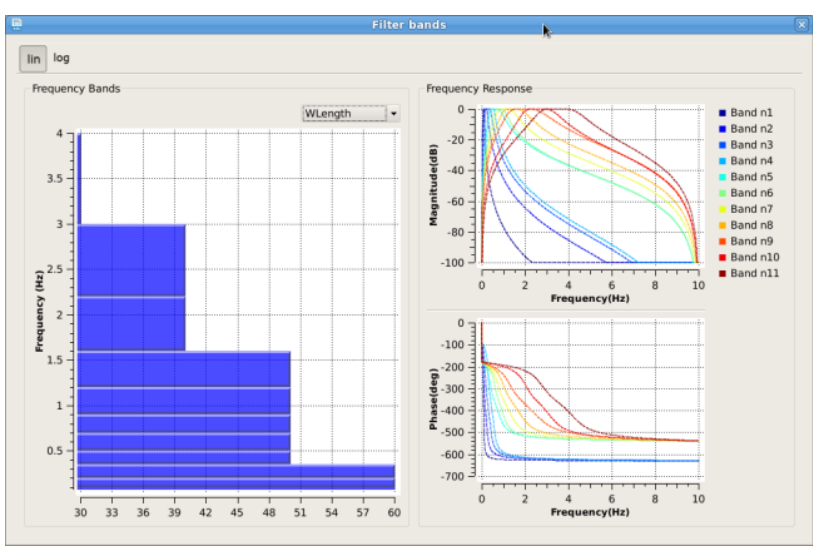

Fig. 2 - Frequency bands used in the data processing. Note that the duration of the windows ( $x$-axis) is variable. The responses in amplitude and phase are presented for each band.

\section{Results}

The cross-correlations carried out made it possible the determination of the parameters with information on frequencies, back azimuths and apparent velocity of the recorded seismic and/or infrasonic signals. From the 10 stations selected for analysis, at only 3 were possible to determine these parameters (I08BO, I09BR and I41PY). At another station (I20EC), it was only possible to obtain the parameters for seismic traces. Figures 3 to 6 show the outputs of the DTK-GPMCC package for the stations I08BO (Bolivia), I09BR (Brazil) and I41PY (Paraguay). At the station I20EC (Ecuador), these parameters were determined only for the seismic traces. The discrimination between the signals was made by the speeds differences (the average speed of seismic waves can vary from 3 to $10 \mathrm{~km} / \mathrm{s}$, while the speed of the infrasound waves is close to the sound propagation speed in the atmosphere $0,344 \mathrm{~km} / \mathrm{s}$ ) and, consequently, due to the differences in the expected arrival times. Table 2 shows the consolidation of the results. 


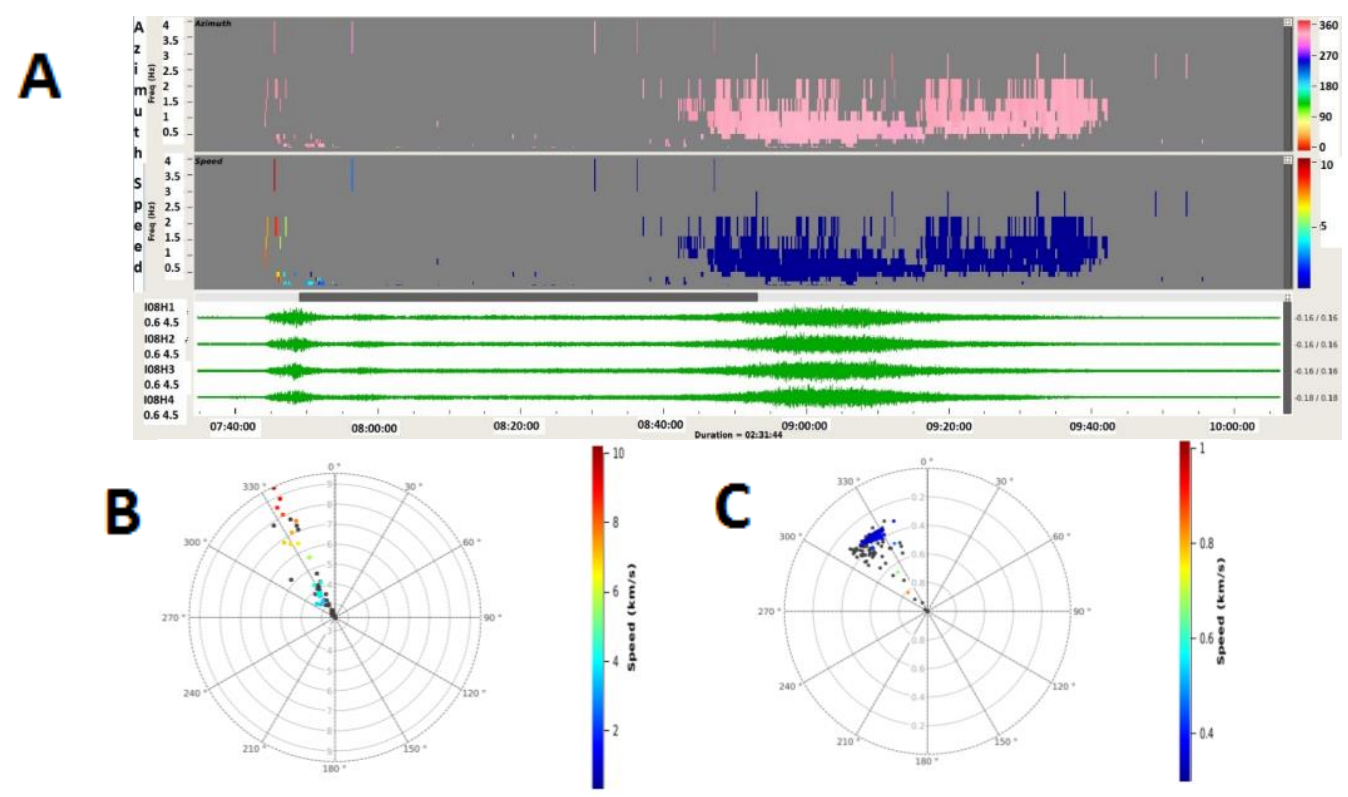

Fig. 3 - In A, detections as a function of azimuth, apparent velocity and frequency, as well as the waveforms of the signals recorded at I08BO station (Bolivia), related to the Peru earthquake M8 in 05/26/2019 at 07h41 UTC. In B and C, speeds and azimuths obtained from the detected seismic signals $(B)$ and of the detected infrasonic signals $(C)$.

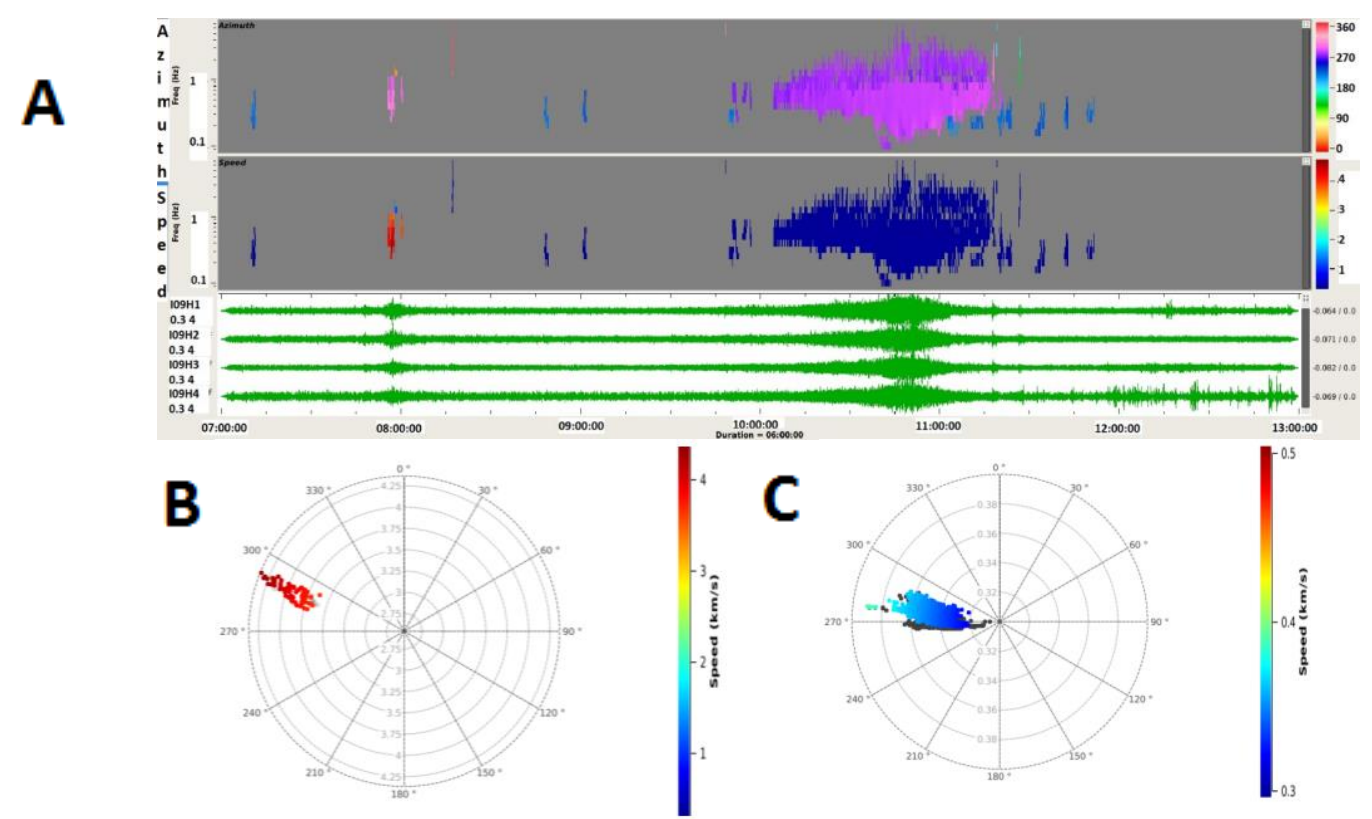

Fig. 4 - In A, detections as a function of azimuth, apparent velocity and frequency, as well as the waveforms of the signals recorded at I09BR station (Brazil), related to the Peru earthquake M8 in 05/26/2019 at 07h41 UTC. In B and C, speeds and azimuths obtained from the detected seismic signals $(B)$ and of the detected infrasonic signals $(C)$. 


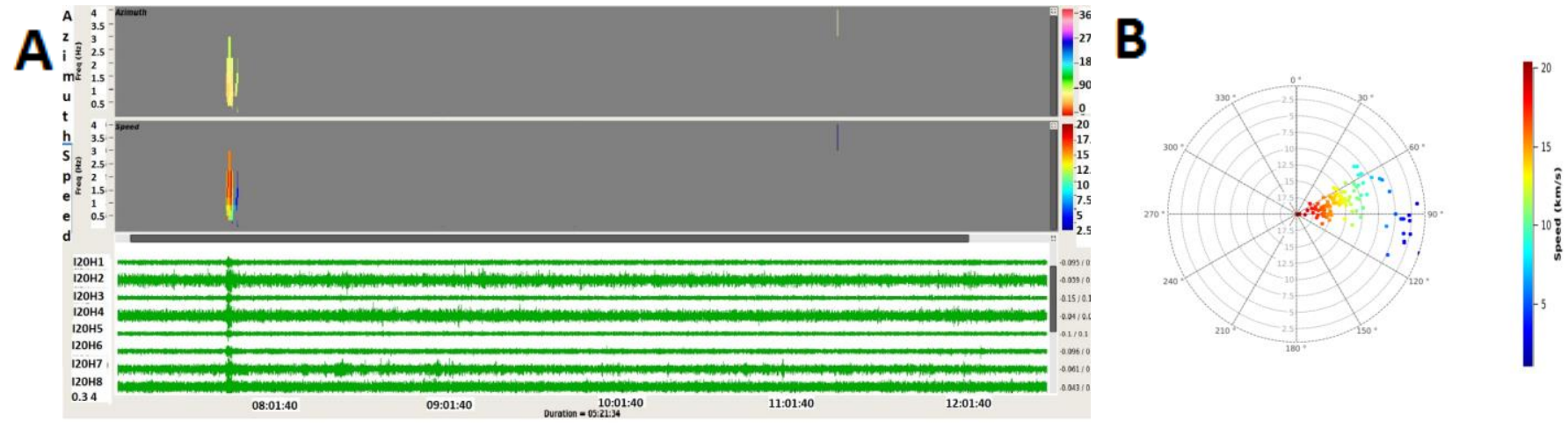

Fig. 5 - In A, detections as a function of azimuth, apparent velocity and frequency, as well as the waveforms of the signals recorded at I20EC station (Ecuador), related to the Peru earthquake M8 in 05/26/2019 at 07h41 UTC. In B, speeds and azimuths obtained from the detected seismic signals. There was no detection of infrasonic signals.

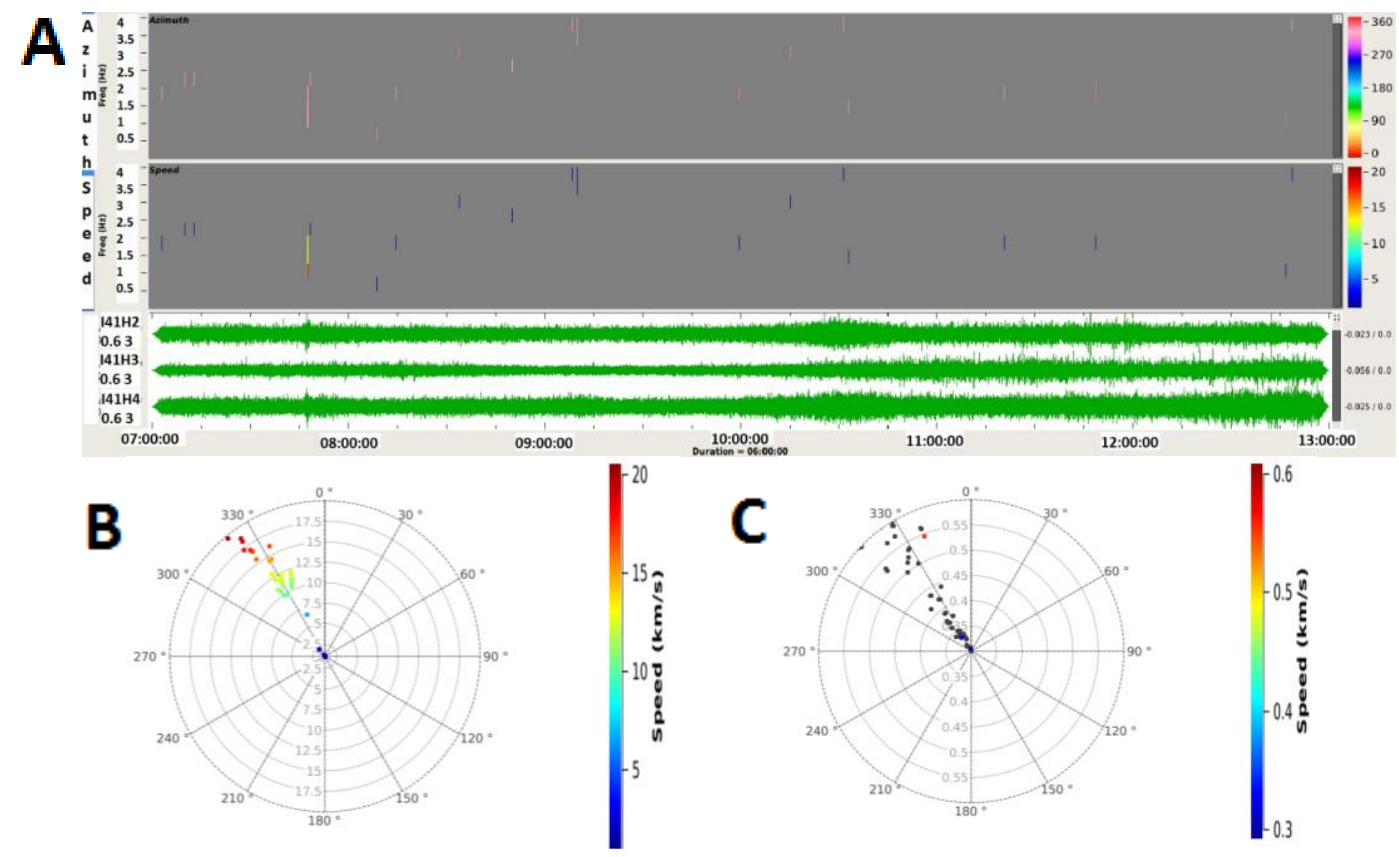

Fig. 6 - In A, detections as a function of azimuth, apparent velocity and frequency, as well as the waveforms of the signals recorded at I41PY station (Paraguay), related to the Peru earthquake M8 in 05/26/2019 at 07h41 UTC. In B and C, speeds and azimuths obtained from the detected seismic signals $(B)$ and of the detected infrasonic signals (C).

Table 2 - Summary table of the seismic and infrasonic parameters determined in the data processing

\begin{tabular}{|c|c|c|c|c|c|c|c|c|}
\hline Station & $\begin{array}{l}\text { Reference } \\
\text { Azimuth } \\
\text { (degrees) }\end{array}$ & $\begin{array}{l}\text { Back } \\
\text { Azimuth } \\
\text { Seismic } \\
\text { Waves } \\
\text { (degrees) } \\
\end{array}$ & $\begin{array}{l}\text { Back Azimuth } \\
\text { Infrasonic } \\
\text { Acoustic } \\
\text { Waves } \\
\text { (degrees) } \\
\end{array}$ & $\begin{array}{l}\text { Aparent Velocity } \\
\text { Seismic Waves } \\
(\mathrm{Km} / \mathbf{s})\end{array}$ & $\begin{array}{c}\text { Aparent Velocity } \\
\text { Infrasonic Acoustic } \\
\text { Waves } \\
(\mathrm{Km} / \mathrm{s})\end{array}$ & $\begin{array}{c}\text { Seismic } \\
\text { Waves } \\
\text { Frequency } \\
(\mathrm{Hz})\end{array}$ & $\begin{array}{l}\text { Infrasonic } \\
\text { Acoustic Waves } \\
\text { Frequency } \\
(\mathrm{Hz})\end{array}$ & $\begin{array}{l}\text { Epicentral } \\
\text { DistancesI } \\
(\mathrm{Km})\end{array}$ \\
\hline I08BO & $326^{\circ}$ & $331^{\circ}+/-6.4^{0}$ & $324^{\circ}+/-2.7^{\circ}$ & $6.2+/-1.9$ & $0.35+/-0.02$ & 0.77 & 0.91 & 1.372 \\
\hline I09BR & $287^{\circ}$ & $281^{\circ}+/-9.1^{\circ}$ & $277^{\circ}+/-4.6^{\circ}$ & $3.2+/-1.1$ & $0.34+/-0.01$ & 0.5 & 1.0 & 3.170 \\
\hline I20EC & $109^{\circ}$ & $77^{\circ}+/-12.3^{\circ}$ & - & $14.6+/-2.4$ & - & 1.6 & - & 1.776 \\
\hline I41PY & $317^{\circ}$ & $329^{\circ}+/-9.6^{\circ}$ & $333^{\circ}-+/-8.5^{\circ}$ & $14.2+/-4.7$ & $0.39-+/-0.11$ & 1.5 & 2.6 & 2.966 \\
\hline
\end{tabular}

\section{Discussion and conclusions}

The analyzed data showed that in three stations, 108BO, I09BR and I41PY, both seismic and infrasoud signals were detected. At another station, I20EC, only seismic signals were detected. This may be due to the non- propagation of the infrasoud wave through the atmosphere, due to the weather conditions not being favorable, toward this station.

It was observed that the apparent velocitys values obtained for the infrasound signals are compatible with the values of the average speed of sound propagation. Apparent velocitys in the portion referring to the detection of seismic signals are compatible with the seismic waves 
Peru earthquake, mag. 8.0 Mw, registered by infrasound stations of the IMS Network

velocity. The azimuth obtained is mostly in accordance with the expected values, considering the margin of error, for the chosen seismic event. Therefore, the analysis of seismic signals from infrasound stations can complement and contribute to the study of seismic events, in synergy of two different technologies, exceeding the initial purpose of infrasound stations, which is the detection of atmospheric explosions and, in the case of stations belonging to the IMS Network, more specifically, nuclear explosions.

\section{References}

Arrowsmith SJ, Burlacu R, Pankow K, Stump B, Stead R, Whitaker R, Hayward C (2012). A seismoacoustic study of the 2011 January 3 Circleville earthquake. Geophys J Int 189:1148- 1158. https://doi.org/10.1111/j.1365246X.2012.05420.x

Barros L, Neri B, Carvalho M, Fontenele D (2020). A participação brasileira na verificação do Tratado de Proibição Total de Testes Nucleares. 1a edição - Editora Copiart - Brasília -

Blanc E, Ceranna L, Hauchecorn A, Charlton Perez A, Marchetti E, Evers L, Kvaerna T, Lastovicka J, Eliasson L, Crosby N, Blanc Benon P, Le Pichon A, Brachet N, Pilger C, Keckhut P. Assink J, Smets P, Lee C, Kero J, Sindelarova T, Kämpfer N, Rüfenacht R, Farges T, Millet C, Näsholm P, Gibbons S, Espy P, Hibbins R, Heinrich P, Ripepe M, Khaykin S, Mze N, Chum J (2018) Toward an improved representation of the middle atmospheric dynamics thanks to the ARISE project. Surv Geophy 39(2):171-225. https://doi.org/10.1007/s10712-017-94440

Brachet N, Brown D, Le Bras R, Mialle P, Coyne J (2010) Infrasound monitoring for atmospheric studies, chapter monitoring the earth's atmosphere with the global IMS infrasound network. Springer, Dordrecht, pp 77-118. ISBN:978-1-4020-9507-8

Brown D, Ceranna L, Prior M, Mialle P, Le Bras RJ (2014) The IDC seismic, hydroacoustic and infrasound global low and high noise models. Pure Appl Geophys 171:361-375

Cansi Y (1995) An automatic seismic event processing for detection and location-the PMCC method. Geophys Res Lett 22:1021-1024

Ceranna L, Matoza R, Hupe P, Le Pichon A, Landès M (2010) Systematic array processing of a decade of global IMS infrasound data In: Le Pichon A, Blanc $E$, Hauchecorne A (eds) Infrasound monitoring for atmospheric studies. Springer, Dordrecht

Christie D, Campus P (2010). The IMS infrasound network: design and establishment of infrasound stations. In: Le Pichon A, Blanc E, Hauchecorne A (eds) Infrasound monitoring for atmospheric studies. Springer, pp 29-75

Cook RK (1971) Infrasound radiated during the Montana earthquake of 1959 August 18. Geophys J R Astr Soc 26:191-198
Dahlman O, Mackby J, Mykkeltveit S, Haak H (2011) Detect and deter: can countries verify the nuclear test ban? Springer Science and Business Media B, Dordrecht, The Netherlands. https:// doi.org/10.1007/978-9-40071676-6

Donn WL, Posmentier ES (1964) Ground-coupled air waves from the Great Alaskan earthquake. J Geophys Res 69:5357-5361

Gibbons S, Kværna T, Näsholm P (2019) Characterization of the Infrasonic Wavefield from Repeating Seismo-Acoustic Events In: Le Pichon A, Blanc E, Hauchecorne A (eds) Infrasound monitoring for atmospheric studies, 2nd edn. Springer, Dordrecht, pp 387-407

Green DN, Guilbert J, Le Pichon A, Sebe O, Bowers D (2009) Modeling ground-to-air coupling for the shallow ML 4.3 Folkestone, United Kingdom, earthquake of 28 April 2007. Bull Seismol Soc Am 99:2541-2552. https://doi.org/10.1785/0120080236

Kim TS, Hayward C, Stump B (2004) Local infrasound signals from the Tokachi-Oki earthquake. Geophys Res Lett 31:L20605. https://doi.org/10.1029/2004GL021178

Le Pichon A, Guilbert J, Vega A, Garces M, Brachet N (2002) Ground-coupled air waves and diffracted infrasound from the Areaquipa earthquake of June 23, 2001. Geophy Res Lett 29 (8):1886-1889

Le Pichon A, Mialle P, Guilbert J, Vergoz J - Multistation infrasonic observations of the Chilean earthquake of 2005 June 13. Geophys. J. Int. (2006) 167, 838-844

Le Pichon A, Matoza R, Brachet N, Cansi Y (2010) Recent enhancements of the PMCC infrasound signal detector. Inframatics Newslett 26:5-8. http://www.inframatics.org

Le Pichon A, Blanc E, Hauchecorne A (2019

) Infrasound monitoring for atmospheric studies. Challenges in middle atmosphere dynamics and societal benefits, 2nd edn. Springer, Dordrecht.

Mialle $\mathrm{P}$, Brown $\mathrm{D}$, Arora $\mathrm{N}$ and colleagues from IDC (2019). Advances in operational processing at the international data centre. In: Le Pichon A, Blanc $E$, Hauchecorne A (eds) Infrasound monitoring for atmospheric studies, 2nd edn. Springer, Dordrecht, pp 209-248

Park J, Stump BW (2014). Seasonal variations of infrasound detections and their characteristics in the western US. Geosci J 19(1):97-111

Walker KT, Hedlin MA (2010). A Review of Wind-Noise Reduction Methodologies. In: Le Pichon A, Blanc E, Hauchecorne A (eds) Infrasound monitoring for atmospheric studies. Springer, Dordrecht 